\title{
Giant cavernoma mimicking a right frontal tumor
}

Louncény Fatoumata Barry $M D^{1}$ iD, El hadji Cheikh Ndiaye Sy $M D^{2}$ iD, Mohameth Faye $M D^{3}$ (D), Momar Code Ba $\boldsymbol{P h D}^{4}$ iD

1,2,3,4Neurosurgery Department, Fann Teaching Hospital, Dakar, Senegal

Date of submission: $27^{\text {th }}$ February 2021

Date of acceptance: $16^{\text {th }}$ August 2021

Date of publication: $1^{\text {st }}$ September 2021

\begin{abstract}
Cavernomas account for 9 to $16 \%$ of cerebrovascular malformations with a prevalence of $0.5 \%$ in the general population. We report a case of a large frontal cavernoma mimicking a frontal tumor and revealed by epileptic seizures. We report a 40-year-old man, without any particular history, received in consultation for tonic-clonic generalized convulsive seizures evolving for 5 years with a normal clinical examination on admission. Cerebral CT scan revealed a large right frontal lesion suggestive of a brain tumor, requiring surgical removal after persistent seizures despite dual antiepileptic therapy. The evolution was favorable at one year with the total cessation of the convulsive seizures without neurological after-effects. In conclusion, giant brain cavernomas are rare lesions and may be mistaken for a brain tumor.
\end{abstract}

Key words: Cavernoma, Epilepsy, Frontal, Giant, Tumor.

\section{Introduction}

Cavis avernous hemangiomas or cavernomas are vascular malformations of the capillary type essentially described in the central nervous system (CNS). They consist of dilated vessels grouped together in the form of cavities or juxtaposed caverns, bordered by an endothelium and fine connective tissue with no interposition of nervous tissue between them. ${ }^{1,2}$ They account for 9 to $16 \%$ of cerebrovascular malformations with a prevalence of $0.5 \%$ in the general population. ${ }^{3}$ In the CNS, $70 \%$ of cavernomas are located in the supratentorial region $25 \%$ in the subtentorial stage and 5\% intramedullary. ${ }^{3}$ Clinical manifestations are variable, ranging from incidental findings to seizures or intracerebral hemorrhage. ${ }^{4}$ Cerebral cavernoma are a condition that is best known

Access this article online
Website: https://www.nepjol.info/index.php/NJN
DOI: https://doi.org/10.3126/njn.v18i3.35271
HOW TO CITE
Barry LF, Sy ECN, Faye M, Ba MC. Giant cavernoma mimicking
a right frontal tumor. NJNS. 2021;18(3):65-8.

Address for correspondence:

Dr. Louncény Fatoumata Barry

Fann Teaching Hospital,

5454 Dakar, Senegal.

E-mail: drlcbarry@gmail.com

Phone: +221 781390566

Copyright (C) 2021 Nepalese Society of Neurosurgeons (NESON)

ISSN: 1813-1948 (Print), 1813-1956 (Online)

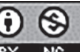

This work is licensed under a Creative Commons Attribution-Non Commercial 4.0 International License. to neuropathologists since its description by Virchow in 1863, and have become part of current neurosurgical practice since the advent of contemporary neuroimaging, CT (computed tomography) and especially magnetic resonance imaging (MRI), which allows direct visualization "in vivo". 5

We report a case of a large frontal cavernoma mimicking a frontal tumor and revealed by epileptic crisis.

\section{Case Report}

A 40-year-old man, without any particular history, is consulted for generalized tonic-clonic convulsive seizures that have been evolving for 5 years. On admission, the clinical examination of this right-handed patient was normal. After the initiation of antiepileptic treatment (phenobarbital $100 \mathrm{mg} /$ day in the evening) and subsequently combined with sodium valproate $(1.5 \mathrm{~g} /$ day in 3 doses) for persistence of seizures, a cerebral CT scan was performed, revealing a large spontaneously hyperdense right frontal mass, rounded in shape, $40 \mathrm{~mm}$ in diameter, surrounded by an edematous reaction, homogeneously enhanced after injection of contrast material, not lysing the bone suggestive of a low-grade glial lesion or meningioma (Figure 1a). MRI was prescribed for a better exploration of the lesion but was not performed due to the patient's lack of financial means. In view of the persistence of epileptic seizures under double antiepileptic treatment, surgical excision was indicated and performed by the right pterional route. The opening of the dura mater revealed an ochre coloration of the right prefrontal cortex, and a trans-cortical approach of the right middle frontal circumvolution was performed after localization of the lesion on digital palpation, revealing a dark red, curled, ecstatic lesion surrounded by perilesional gliosis evoking a cavernoma (Figure 2). 


\section{Barry et al}

A macroscopically complete excision associated with excision of the perilesional glial tissue (Figure 1b) was performed under the operating microscope. The diagnosis of cavernoma was confirmed by anatomopathological examination of the surgical specimen. The immediate postoperative course was favorable with an extubation at 2 hours from the end of the operation and a Glasgow score of 15 with no sensitive-motor deficits. At 24 hours postoperatively, the patient presented a state of convulsive, requiring re-intubation and treated with Midazolam 0.15 $\mathrm{mg} / \mathrm{kg}$ /day combined with Levetiracetam $1000 \mathrm{mg} /$ day, allowing a complete cessation of seizures at 48 hours and extubation. The patient was discharged at one week of hospitalization on Levetiracetam $1000 \mathrm{mg}$ /day in 2 daily doses. The antiepileptic treatment was gradually stopped at 6 months without the appearance of new seizures. The evolution at one year was marked by a total cessation of seizures without any further neurological sequelae.
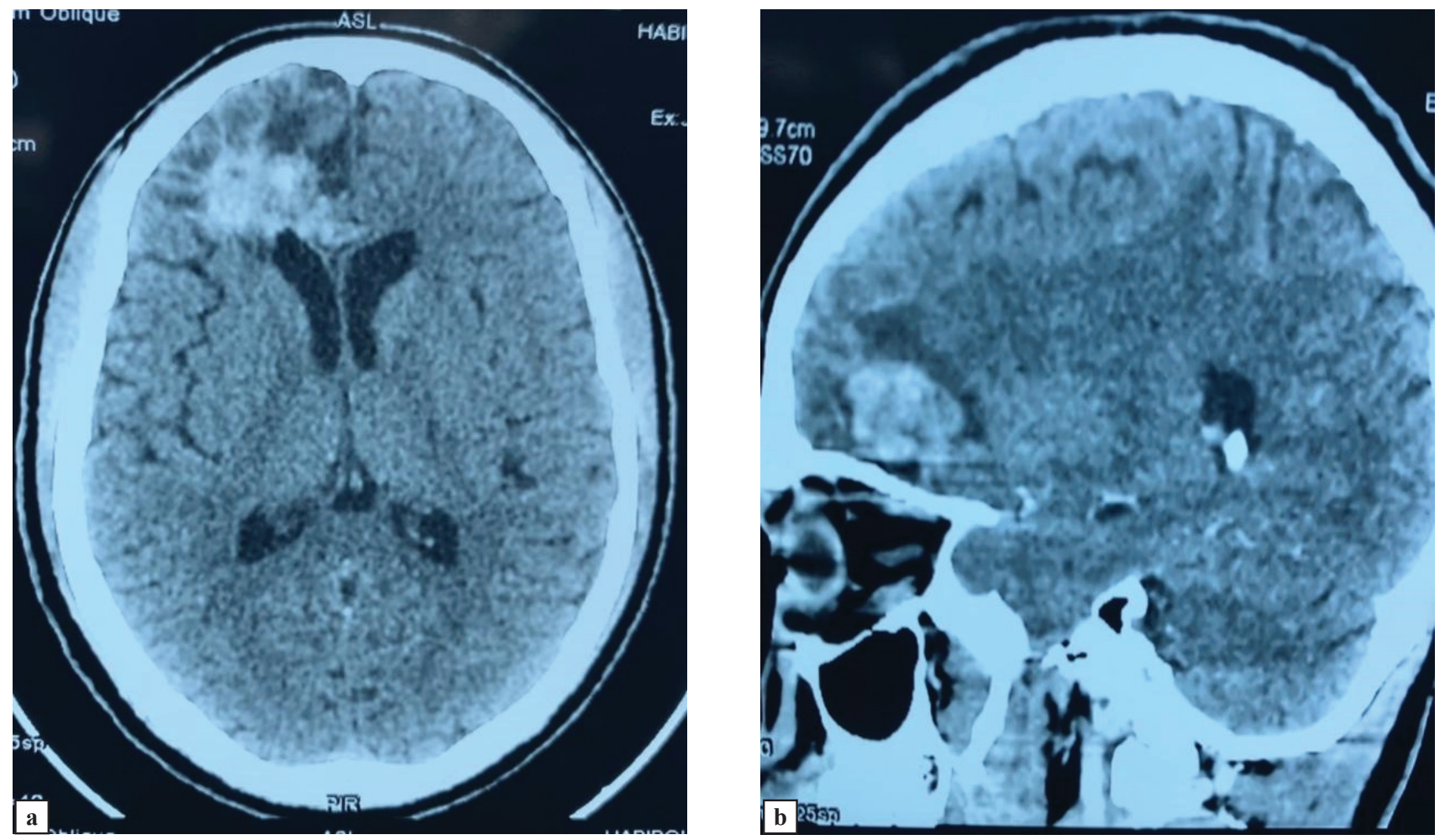

Figure 1: Cerebral CT scan without and with contrast injection.

1a: Non-injected axial section: spontaneously hyperdense, spontaneously hyperdense straight frontal lesion, rounded in shape, measuring $40 \mathrm{~mm}$, with spiculate contours, surrounded by an edematous reaction.

1b: Injected sagittal section: slight enhancement after injection of contrast medium.

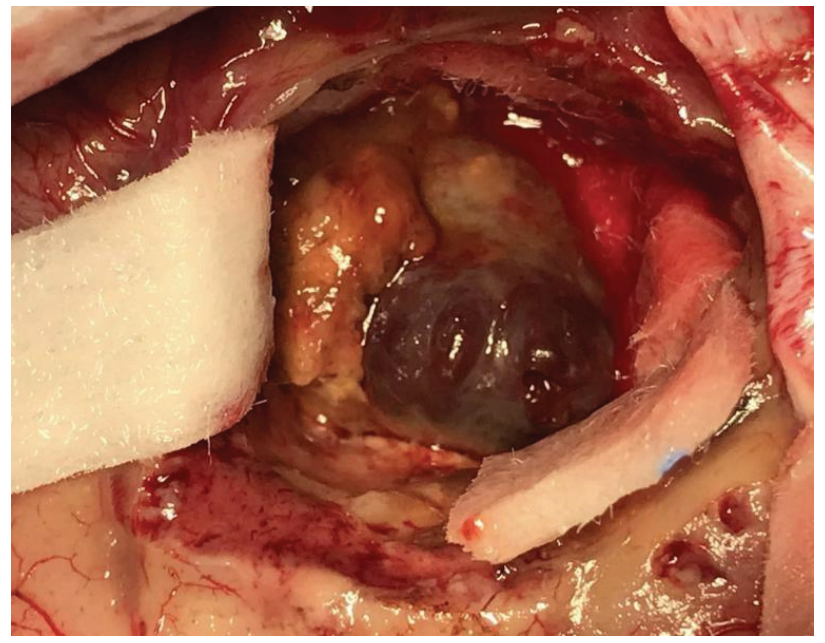

Figure 2: Intraoperative image: dark red, puddled, ecstatic lesion surrounded by periwinkle gliosis. 

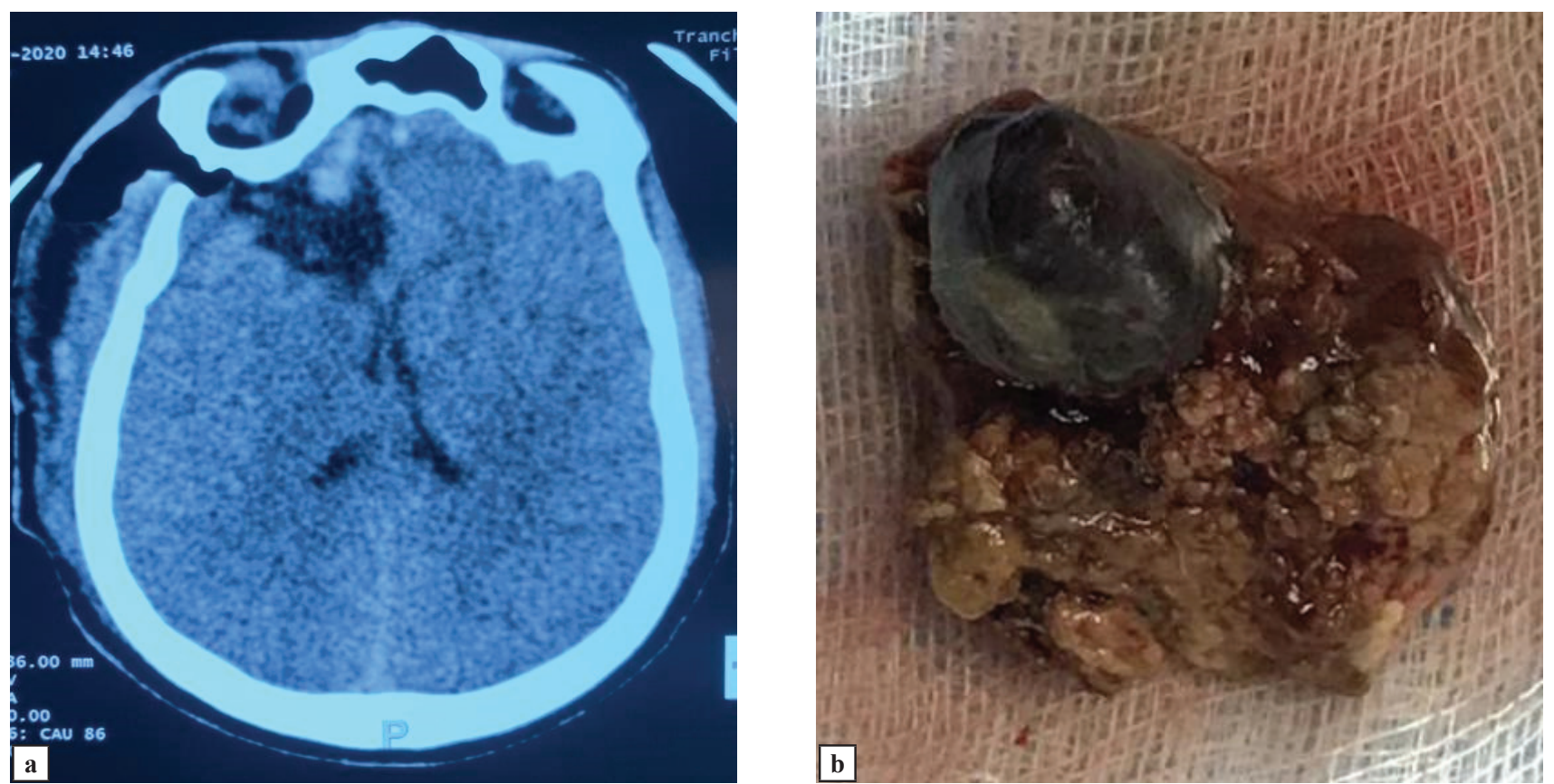

Figures 3a: Postoperative image in axial section: Macroscopically complete resection with presence of the frontal operating cavity.

3b: Operating room: Dark red lesion surrounded by an ochre-colored glial parenchyma.

\section{Discussion}

CNS cavernomas are vascular malformations that occur in two circumstances: sporadic forms and autosomal dominant familial forms. ${ }^{3}$ The lesion consists of enlarged, dystrophic, blood-filled vessels, without interposition of cerebral parenchyma, surrounded by hemosiderin and gliosis, sometimes calcified. ${ }^{6}$ In $80 \%$ of sporadic forms, the lesion is single, multiple lesions are rare. In familial forms, lesions are always multiple. ${ }^{6}$

Cavernomas are often associated with other vascular malformations, especially venous developmental abnormalities, which must be imperatively respected in order to avoid creating venous infarction that could jeopardize the vital and/or functional prognosis. ${ }^{4,6}$

This is an angiographically occult malformation that can be explained by the juxtaposition of "cavernous" blood cavities without afferent or efferent vessels. ${ }^{7}$

These cavernomas generally become symptomatic between the second and fifth decade. The most common symptoms include seizures and focal neurological symptoms due to bleeding or parenchymal compression by the cavernoma. ${ }^{8}$ Epilepsy was the mode of disclosure of the lesion in our patient. Indeed, an epileptic seizure is inaugural in $16 \%$ to over $60 \%$ of cases depending on the series. ${ }^{9-12}$ These seizures can be partial, complex or generalized, unique or old. The frequency may be several times a week or daily and sometimes more than three seizures a day despite treatment. ${ }^{13}$ Contrary to our patient, it is generally accepted that these epilepsies are easily controlled by medical treatment except in the temporal localizations. ${ }^{14,15}$

After decades during which they were first and foremost autopsy discoveries, cavernomas have become a common neurosurgical practice since the advent of contemporary CT and especially MRI neuro-imaging, which makes it possible to diagnose them "in vivo". ${ }^{5}$ MRI is the reference examination for diagnosis. It is also used for follow-up, performed every one to two years in the absence of clinical manifestations. ${ }^{8}$ However, its high cost and low availability in developing countries limit its accessibility. Our patient's diagnosis was made by CT scan.

The size of the cavernomas is highly variable, the largest observed by Russell and Rubinstein ${ }^{2}$ was $4 \mathrm{~cm}$ along the longer axis, occupying the third ventricle, the septum lucidum and the horn of the right ventricle. However, most cavernomas are less voluminous, measuring 1 to $2 \mathrm{~cm}$ in diameter. Like Rubinstein and Russell's, our patient also had a large cavernoma ( $40 \mathrm{~mm}$ in diameter) located in the right frontal lobe.

From an anatomopathological point of view, it should be remembered that cavernoma is a very limited lesion and, unlike an arteriovenous malformation, there is no interposition of brain tissue between the caverns. Moreover, repeated microhemorrhages will cause peri 


\section{Barry et al}

cavernomatous gliosis and hemosiderin deposits, a nonfunctional tissue that will be useful to the neurosurgeon by serving as a cleavage plane at dissection. ${ }^{4}$

On the surgical level, there seems to be a consensus regarding the surgical nature of cerebral cavernomas as long as they are symptomatic. Supratentorial cavernomas, which are the most frequent, are a well-identified cause of epilepsy; even if the epilepsy is chemosensitive, the indication for removal of the causal cavernoma seems to be absolute ${ }^{5}$. The surgical risk has become almost nil in the surgery of supratentorial epileptogenic cavernomas, and many patients who have undergone surgery have seen their seizures disappear completely and definitively and have been able to stop their treatment ${ }^{5}$, as in the case of our patient.

\section{Conclusion}

Giant cerebral cavernomas are lesions rarely reported in the literature; their appearance on imaging may mimic a brain tumor as in our patient.

\section{Conflict of Interest: None}

Source(s) of support: None

\section{References}

1. Li DY, Whitehead KJ. Evaluating strategies for the treatment of cerebral cavernous malformations. Stroke. 2010;41(10 Suppl):S92-4. https://doi. org/10.1161/strokeaha.110.594929

2. Russel D, Rubinstein L. Pathology of tumours of the nervous system. 5th ed, Baltimore, Williams and Wilkins, 1989.

3. Melot A, Laquerrière A, Hanzen S, Freger P, Proust F. Cavernome radio-induit du système nerveux central. À propos d'un cas Radiation-induced cavernoma of the central nervous system. Neurochirurgie. 2007;53:495-500. https://doi.org/10.1016/j. neuchi.2007.09.147

4. Khouri S, Leal PL, Guarnieri J, Borha A, Gadan $\mathrm{B}$, et al. Traitement chirurgical des cavernomes corticaux et sous-corticaux. Principes généraux et série personnelle de 20 cas opérés entre 2000 et 2006. Neurochirurgie. 2007;53:163-7. https://doi. org/10.1016/j.neuchi.2007.02.013
5. Houtteville JP. Les cavernomes du système nerveux central. Historique et évolution des idées. Neurochirurgie. 2007;53:117-21. https://doi. org/10.1016/j.neuchi.2007.02.003

6. Mosnier J-F, Brunon J, Nuti C. Anatomie pathologique des cavernomes du système nerveux central. Neurochirurgie. 2007;53:131-5. https://doi. org/10.1016/j.neuchi.2007.02.004

7. Menany M, Sator H, Lamhamedi S, Latib R, Chami I, Boujida MN. Imagerie du cavernome cérébral. Feuillets de radiologie. 2015:30;1-2.

8. De Jong A, Benayoun L, Bekrar Y, Forget S, Wernet A. Anesthésie obstétricale chez des patientes porteuses de cavernomes cérébraux : à propos de deux cas. Annales Françaises d'Anesthésie et de Réanimation. 2012;31:635-7. https://doi. org/10.1016/j.annfar.2012.02.020

9. Buckingham NJ, Crone KR, Ball WS, Berger TS. Management of cerebral cavernous angiomas in children presenting with seizures. Child's Nervous System. 1989;5:347-9. https://doi.org/10.1007/ bf00271890

10. Di Rocco C, Ianelli A, Tamburrini, G. Cavernous angiomas of the brainstem in children. Pediatric Neurosurgery. 1997;27:92-9. https://doi. org $/ 10.1159 / 000121233$

11. Fortuna A, Ferrante L, Mastronardi L, Acqui M, d'Addetta R. Cerebral cavernous angioma in children. Child's Nervous System. 1989;5:201-7. https://doi.org/10.1007/BF00271020

12. Scott RM, Barnes P, Kupsky W, Adelman RS. Cavernous angiomas of the central nervous system in children. Journal of Neurosurgery. 1992;76:38-46. https//doi.org/10.3171/jns.1992.76.1.0038

13. Lena G, Ternier J, Paz-Paredes A, Scavarda D. Cavernomes du système nerveux central chez l'enfant. Neurochirurgie. 2007;53:223-37. https:// doi.org/10.1016/j.neuchi.2007.02.011

14. Iakovlev G, Devaux B, Ghossoub M, Beuvon F, Brami F, Roux FX. Cavernomes intracrâniens, épilepsie et crises d'épilepsie. Histoire naturelle et modalités thérapeutiques. Neurochirurgie. 2005;51:3-14 https://doi.org/10.1016/s0028-3770(05)83414-9

15. Moran NF, Fish DR, Kitchen N, Shorvon S, Kendall BE, Stevens JM. Supratentorial cavernous haemangiomas and epilepsy: A review of the literature and case series. Journal of Neurology, Neurosurgery, and Psychiatry. 1999;66:561-8. 